\title{
Analisis Potensi Tsunami Menggunakan Mekanisme Fokus (Studi Kasus Gempa 15 November 2014
}

\author{
Aprillya J.G Arikalanga, Guntur Pasaua*, Ferdya* \\ aJurusan Fisika, FMIPA, Unsrat, Manado
}

KATA KUNCI

Mekanisme Bola Fokus

Sesar/Patahan

\begin{abstract}
A B S T R A K
Lempeng laut Maluku merupakan lempeng mikro yang berada di antara lempeng mikro Sangihe dan Halmahera yang bergerak berlawanan arah, kondisi ini mengakibatkan kegempaan daerah Sulawesi Utara dan sekitarnya terkonsentrasi di sebagian besar wilayah Laut Maluku dan sisanya terjadi di Laut Sulawesi. Adapun tujuan penelitian ini adalah untuk menentukan karakterisik pola patahan akibat gempabumi tanggal 15 November 2014 di Laut Maluku koordinat $1^{\circ} \mathrm{LS}$ - $3^{\circ} \mathrm{LU}$ dan $120^{\circ}-130^{\circ}$ BT dengan sumber data dari katalog gempa bumi USGS dan Global Centroid Momen Tensor. Analisis bola fokus bahwa gempa tanggal 14 November 2014 dengan koordinat $1^{0}$ LS - $3^{\circ}$ LU dan $120^{\circ}-130^{\circ}$ BT adalah kombinasi sesar mendatar dan sesar naik atau jenis sesar ini disebut juga oblique. Hasil analisis menggunakan Sofware WinITDB dan perhitungan rumus empiris menunjukkan bahwa terjadi deformasi di dasar laut 1,409 m, yang menyebabkan terjadinya Tsunami yang kecil, karena deformasi yang terjadi belum cukup kuat pengaruhnya untuk merobek permukaan dasar laut.
\end{abstract}

KEYW OR D S

Focal Mechanism

Fault

TERSEDIA ONLINE

01 Februari 2018

1. Pendahuluan

Indonesia terletak pada batas pertemuan tiga lempeng besar dunia yang sangat aktif yaitu lempeng Eurasia, lempeng Pasifik, dan lempeng Indo-Australia serta satu lempeng mikro yaitu lempeng mikro Filipina, karena itu maka wilayah Indonesia sangat rawan terhadap bencana gempa tektonik (Pasau, 2011).
Lempeng laut Maluku merupakan lempeng mikro yang berada di antara lempeng mikro Sangihe dan Halmahera yang bergerak berlawanan arah, kondisi ini mengakibatkan kegempaan daerah Sulawesi Utara dan sekitarnya terkonsentrasi di sebagian besar wilayah Laut Maluku dan sisanya terjadi di Laut Sulawesi. 


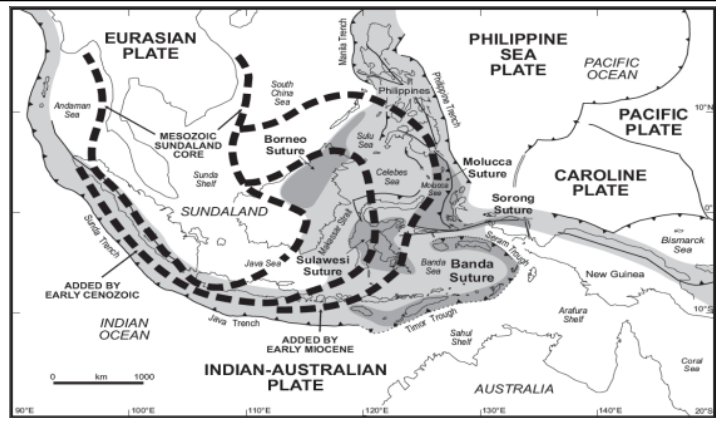

Gambar 1. Zona Batas Lempeng Indonesia

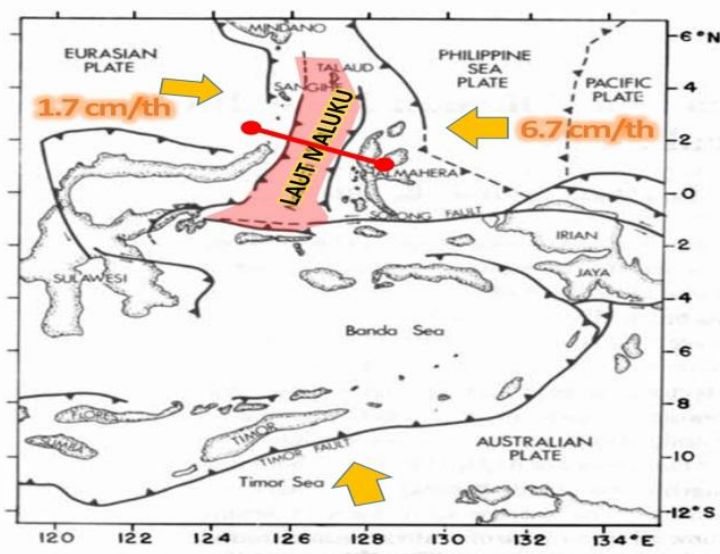

Gambar 2. Subduksi Ganda Laut Maluku

Gempabumi dengan magnitude 7.3 SR tanggal 15 November 2014 merupakan salah satu contoh gempa berskala besar yang terjadi di Laut Maluku dengan koordinat $1^{\circ} \mathrm{LS}-3^{\circ} \mathrm{LU}$ dan $120^{\circ}-130^{\circ} \mathrm{BT}$. Secara toritis, gempa yang terjadi sudah memenuhi kriteria gempa yang mengakibatkan tsunami. Namun kenyataannya tidak ada tsunami yang terjadi. Maka dianggap perlu untuk menganalisis penyebab tidak adanya tsunami meskipun gempa yang terjadi memenuhi kriteria terjadinya tsunami.

Penentuan pola patahan gempa dalam penelitian ini menggunakan mekanisme bola focus. Dengan menentukan pola patahan, hasil yang diperoleh diharapkan berupa pola patahan yang dominan di daerah laut Maluku. Penentuan pola patahan dominan Laut Maluku dikaitkan dengan gempa 7.3 SR tanggal 15 November 2014 untuk melihat proyeksi bola fokus yang didapat kemudian akan diketahui penyebab tidak terjadinya tsunami pada gempa besar tersebut.

\section{Material dan Metode}

Dalam penelitian ini data yang digunakan adalah data sekunder berupa data kejadian gempa bumi periode 11 Desember - 21 Desember 2014 yang diperoleh dari katalog gempa bumi USGS dan Global Centroid Momen Tensor (Global CMT) dan International Seismological Center (ISC).

Data gempa yang dianalisis berupa data kejadian gempa bumi dengan batas daerah penelitian yaitu $1^{0} \mathrm{LS}-3^{\circ} \mathrm{LU}$ dan $120^{\circ}-130^{\circ} \mathrm{BT}$, kedalaman 1 - $60 \mathrm{Km}$ (gempa dangkal). Parameter gempa bumi yang digunakan dalam penelitian ini berupa lokasi episenter (sumber gempa bumi), magnitude, dan kedalaman sumber gempa bumi serta parameter bola fokus berupa data polarisasi awal gelombang gempa pada stasiun pengamat. Metode penelitian yang digunakan adalah metode analisis deskriptif.

\section{Hasil dan Pembahasan}

\subsection{Mekanisme Bola Fokus (Focal Mechanism)}

Data parameter gempabumi berupa posisi lintang dan bujur lokasi kejadian gempa bumi yang kemudian diproses menggunakan bantuan software Mirone. Software ini membantu memproyeksikan bidang sesar berupa bola fokus untuk kejadian gempa bumi secara otomatis dengan menggunakan data katalog Global CMT (Centroid momen Tensor) berupa data strike, dip dan slip. Data yang digunakan bisa diakses langsung ketika akan menggunakan software mirone dengan koneksi data internet. Hasil dari keluaran Mirone berupa gambar bola fokus yang dapat di plot otomatis ketika dimasukkan data strike $42^{\circ}$, dip $35^{\circ}$, dan rake $110^{\circ}$. Berdasarkan Mirone keluaran bola fokus yaitu Oblique naik, yaitu kombinasi antara sesar mendatar dan sesar naik. Dari keluaran mekanisme bola focus yakni oblique naik sehingga gempa tanggal 14 November 2014 menyebabkan tsunami.

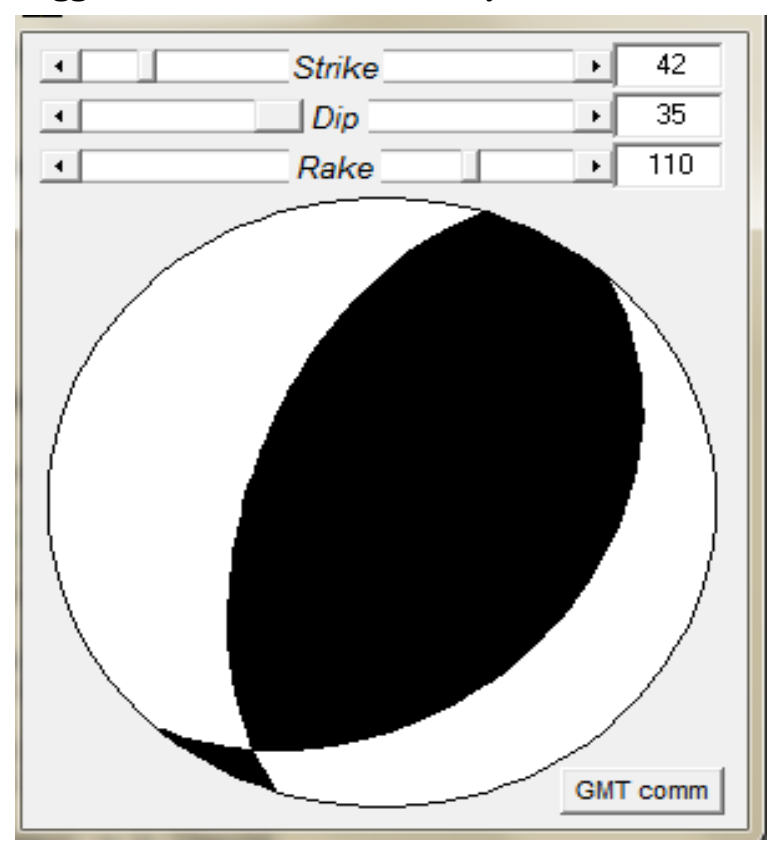

Gambar 3. Hasil Keluaran fokal menggunakan Mirone

3.1. Hasil perhitungan panjang patahan, lebar patahan, dan pergeseran dasar laut

Perhitungan menggunakan yang digunakan untuk menghitung parameter patahan (Wells dan Coppersmith, 1994). Dengan hasil sebagai berikut :
Magnitude Gempa
: $7.3 \mathrm{SR}$
Panjang Patahan
: 43,651 Km
Lebar Patahan
: $26.001 \mathrm{Km}$
Pergeseran Dasar Laut
: $1,409 \mathrm{~m}$

Hasil perhitungan digunakan dalam proses pembuatan simulasi Tsunami menggunakan software WinITDB. 


\subsection{Simulasi Tsunami Menggunakan Software WinITDB}

Langkah pertama yang dilakukan untuk membuat simulasi Tsunami yaitu menyiapkan data yaitu data sumber gempa berupa lintang, bujur daerah tunjangan tsunami, hasil perhitungan panjang patahan, lebar patahan, deformasi vertikal tanggal 14 November 2015.

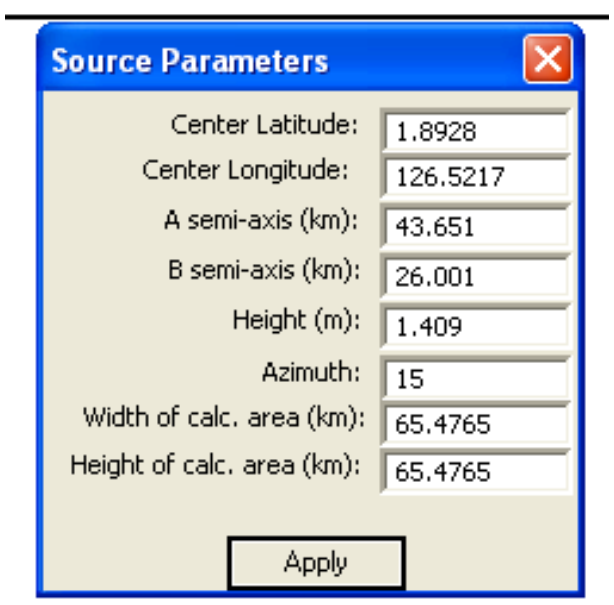

Gambar 4. Parameter Gempa

Data yang ditulis dalam source parameter selanjutnya akan digunakan sebagai data utama untuk pembuatan simulasi Tsunami.

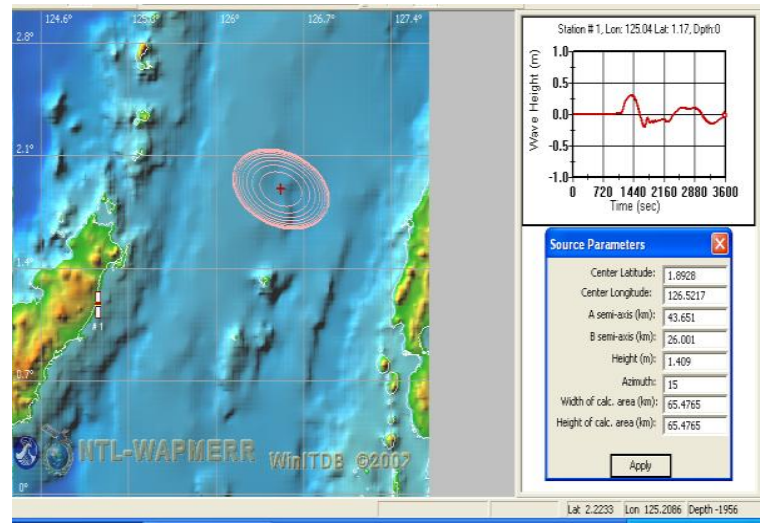

Gambar 5. Simulasi Tsunami menggunakan Software WinITDB

Station \# 1, Lon: 125.04 Lat: 1.17. Dpth:0

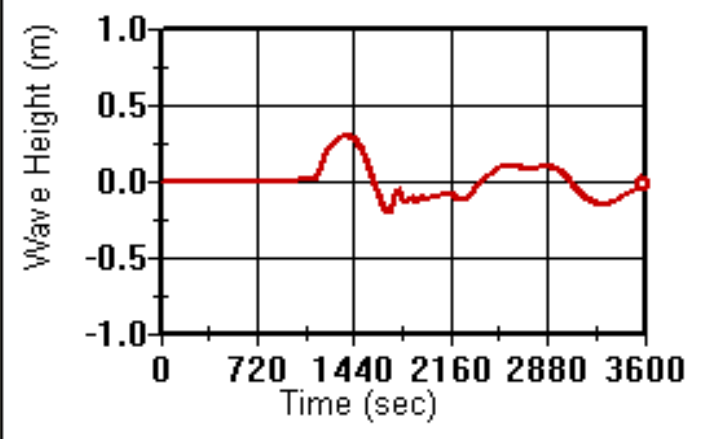

Gambar 6. Run Up simulasi Tsunami

Dari hasil simulasi yang dilakukan terlihat bahwa ada kenaikan air di permukaan yaitu 0,3 meter di 1.8928 LU dan 126.5217 BT, lokasi berada di utara Laut Maluku yaitu di $158 \mathrm{~km}$ Timur Laut Bitung atau $160 \mathrm{~km}$ Barat Laut Ternate. Run up (ketinggian air saat mencapai permukaan) di tunjukan dengan garis berwarna merah, yang terjadi di pesisir laut Manado.

Tsunami yang terjadi tidak dapat dilihat secara langsung oleh manusia, dikarenakan kekuatan tsunaminya kecil yaitu $0.3 \mathrm{~m}$ hanya dapat dibaca lewat hasil simulasi dengan WinITDB. Dilihat dari kecilnya intensitas gelombang tsunami secara kasat mata tidak dapat dilihat ataupun dirasakan oleh orang sekitar. Kejadian tsunami dilihat menggunakan alat khusus pendeteksi tsunami dengan meninjau kecepatan gelombang yang tinggi dan periodenya yang panjang.

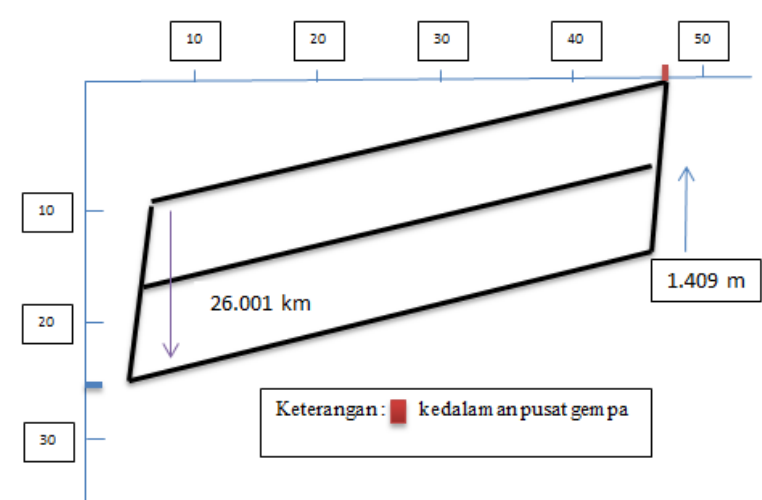

Gambar 7. Skema kondisi ekstrim gempa Laut Maluku berdasarkan panjang dan lebar patahan

Gambar skema menjelaskan kondisi ekstrim gempa 15 November 2014 dengan kedalaman yaitu $48 \mathrm{Km}$ di bawah permukaan, lebar patahan 26.001 $\mathrm{km}$ dan dislokasi (pergeseran) sesar sebesar 1.409 $\mathrm{m}$. Dilihat dari syarat terjadinya tsunami, gempa 7.3 SR ini seharusnya menimbulkan Tsunami yang cukup besar, namun setelah dilakukan perhitungan dislokasi sesar dapat dilihat bahwa pergerakkan yang terjadi sangat kecil. Salah satu penyebab yaitu adanya kombinasi sesar yang terbentuk yaitu kombinasi antara sesar mendatar dan sesar naik (oblique).

\subsection{Pemetaan Data Aftershock dan Mainshock}

Berdasarkan gempa, setelah di plot terlihat bahwa pola patahan yang terbentuk untuk kejadian gempa 15 November 2014 adalah sesar kombinasi antara sesar mendatar dengan sesar naik atau disebut sesar oblique.

Gempa_Laut_Maluku

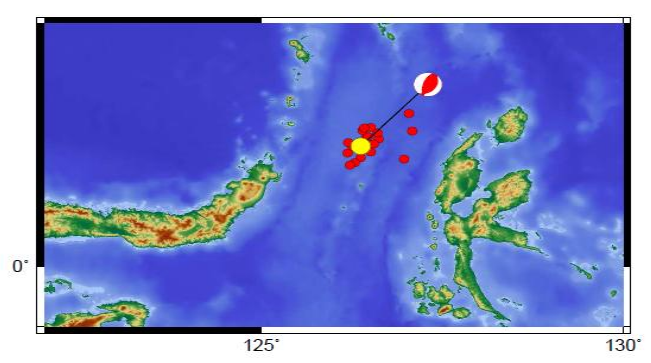

Gambar 8. Peta After Shock dan Mainshock 


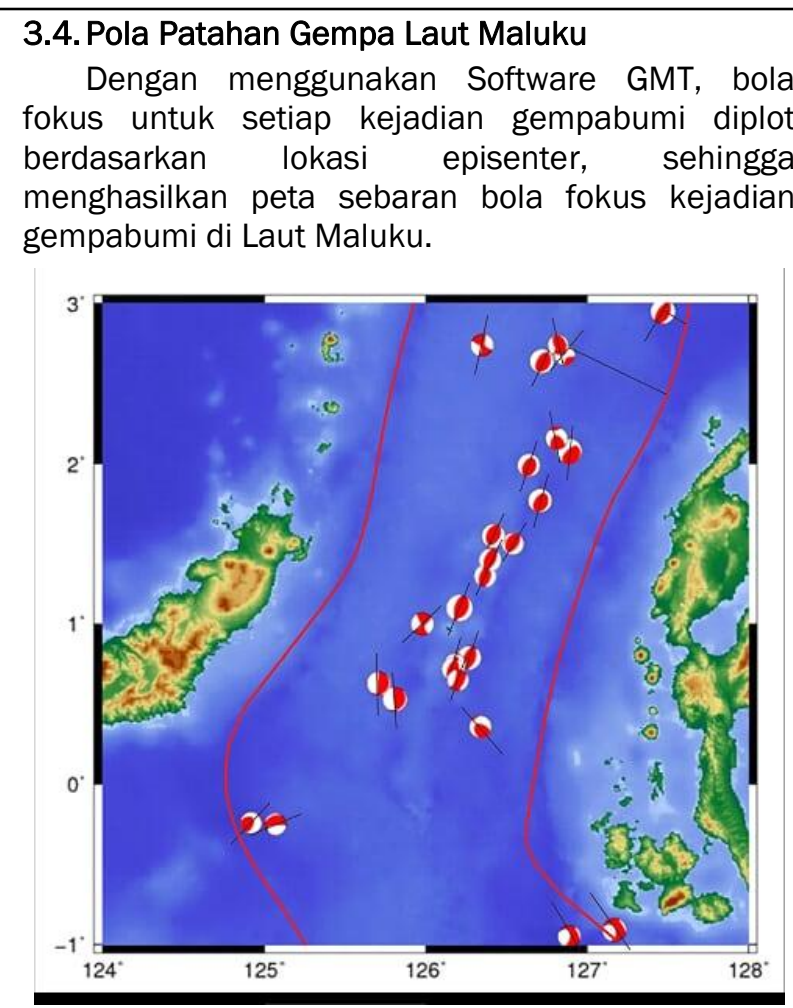

Gambar 9. Pola Patahan Gempa bumi Laut Maluku

Berdasarkan peta sebaran pola patahan wilayah Laut Maluku, jenis sesar yang dominan adalah sesar naik atau yang disebut thrust fault. Sesar lain yang terbentuk yaitu sesar mendatar (strike slip fault). Hal ini kemungkinan besar disebabkan karena adanya gerak lempeng Halmahera yang relatif berlawanan dengan arah gerak lempeng Sangihe. Kedua lempeng tersebut bergerak saling menekan lempeng Laut Maluku yang posisinya berada diantara kedua lempeng tersebut. Lempeng Halmahera cendurung bergerak relatif ke arah Barat dan lempeng Sangihe relatif ke arah Timur.

\section{Kesimpulan}

1. Berdasarkan analisis mekanisme bola fokus, menunjukkan bahwa gempa tanggal 14 November 2014 dengan koordinat $1^{0} \mathrm{LS}-3^{\circ} \mathrm{LU}$ dan $120^{\circ}$ - $130^{\circ}$ BT adalah kombinasi sesar mendatar dan sesar naik atau jenis sesar ini disebut juga oblique.

2. Berdasarkan analisis hasil software WinITDB dan perhitungan menggunakan rumus empiris terjadi deformasi di dasar laut yang tidak terlalu kuat yaitu 1,409 m. Hal ini yang menyebabkan terjadinya Tsunami yang kecil, karena deformasi yang terjadi belum cukup kuat pengaruhnya untuk merobek permukaan dasar laut.

\section{Daftar Pustaka}

Ibrahim, G dan Subardjo. 2005. Pengetahuan Seismologi. Badan Meteorologi dan Geofisika, Jakarta

Ismullah, M.F, Lantu, S. Aswad, dan Massinai M.A. 2015 Tectonics Earthquake Distribution Pattern Analysis Based Focal Mechanisms (Case Studi
Sulawesi Island, 1993-2912). Ip Cof. Proc. 1658: 030013-1-030013-10. http//dx.doi.org/10.1063/1.4815021 November 2017]

Nielsen, P. 2007. Aktivitas Gempa Laut Maluku. Badan Meteorologi dan Geofisika, Jakarta.

Pasau, G. 2011. Respons Spektra Gempabumi di Batuan Dasar Kota Bitung Sulawesi Utara Pada Periode Ulang 2500 Tahun. Jurnal IImiah Sains. 11: $13-19$

Pasau, G. dan A. Tanauma. 2011. Pemodelan Sumber Gempa di Wilayah Sulawesi Utara Sebagai Upaya Mitigasi Bencana Gempabumi. Jurnal IImiah Sains

Pribadi, S., Afnimar., Puspito, N.T dan Ibrahim, G. 2013. Characteristic of Earthquake-Generated Tsunamis in Indonesia Based on Source Parameter Analysis. J. Math.Fund. Sci. 45: 2: 189-207 [9 November 2017]

Raharjo, S.S. 2013. Pemetaan Daerah Rawan Tsunami di Wilayah Pesisir Kema Sulawesi Utara [Tesis]. Pascasarjana Universitas Sam Ratulangi, Manado

Stein S. dan Wysession, M. 2003. An Introduction to Seismology Earthquake and Earth Structure. Geolmag. 140:727-735

Wells, D.L dan Coopersmith, K.J.1994. New Empirical Relationships among Magnitudo, Rupture Length, Rupture Width, Rupture Area, and Surface Displacement. Buletin of The Seismological Sociciety of America. 84:9741002. 